\title{
EXTENSIÓN UNIVERSITARIA Y UNIVERSIDADES POPULARES: EL MODELO DE EDUCACIÓN LIBRE EN LA UNIVERSIDAD POPULAR MEXICANA (1912-1920)
}

\author{
Dr. Morelos Torres Aguilar ${ }^{1}$ \\ Universidad Autónoma de Chiapas- México \\ Grupo de Investigación HISULA-SHELA \\ morelostorres@gmail.com
}

Recepción: 30/05/2008

Evaluación: $23 / 02 / 2009$

Aceptación: 25/03/2009

Articulo de Reflexió

\section{RESUMEN}

El artículo es resultado de una investigación sobre la extensión universitaria y las universidades populares, vistas como modelos alternativos de educación a principios del Siglo XX en Europa y América. El trabajo se centra en la Universidad Popular Mexicana, cuyo modelo educativo se pretende examinar, reconstruir y comparar con los de instituciones similares de la época. Se muestra así que mediante el modelo de educación libre aplicado en estos centros de estudios, fue posible que la población en general tuviera acceso a la educación superior.

Palabras Clave: Universidad Popular, Extensión Universitaria, Modelo, Educación Libre, Intelectuales.

\footnotetext{
1 Doctor en Historia de la Universidad Nacional Autónoma de México. Obtuvo mención honorífica y la medalla Alfonso Caso de esta institución por sus estudios de doctorado. Actualmente es profesor de tiempo completo en la Facultad de Ciencias Sociales de la Universidad Autónoma de Chiapas, líder del Cuerpo Académico de Estudios Históricos y coordinador regional del Seminario Nacional de Música de la Nueva España y el México Independiente [MUSICAT, UNAM-PAPIIT, CONACYT]. Investigador del grupo Historia y Prospectiva de la Universidad Latinoamericana HISULA.
} 


\title{
UNIVERSITY EXTENSION AND POPULAR UNIVERSITIES: THE FREE EDUCATION MODEL AT THE UNIVERSIDAD POPULAR MEXICANA (1912-1920)
}

\author{
Dr. Morelos Torres Aguilar \\ Universidad Autónoma de Chiapas- México \\ HISULA-SHELA Research Group \\ morelostorres@gmail.com
}

\begin{abstract}
The article results from a research on the university extension and the popular universities, seen as alternative models of education at the beginning of the XX century in Europe and America. The research focuses specifically on the Mexican Popular University (Universidad Popular Mexicana), whose educational model is intended to examine, reconstruct and compare with the others belonging to similar institutions of that time. It is to show that the application of the free model of education in those educational centers let the population, in general, have access to the higher education.
\end{abstract}

Key Words: popular university, university extension, model, free education, erudites.

\section{INTRODUCCIÓN}

"El presente artículo recoge y desarrolla algunas de las líneas de investigación expuestas en un trabajo más extenso acerca de la Universidad Popular Mexicana (UPM), elaborado por el autor como tesis de doctorado." ${ }^{2}$ En particular, el estudio de dicha institución desembocó, en aquella investigación, en la necesidad de caracterizar, precisar y definir el modelo de universidad al que pertenecía el centro educativo. El primer problema que plantea la definición de este modelo consiste en que las universidades populares en general, y la UPM en particular, no corresponden a los modelos más conocidos de universidad que funcionaban en el mundo durante las primeras dos décadas del siglo XX, es decir el modelo de universidad profesionalizante y el modelo de

2 TORRES AGUILAR, Morelos. (2006): La Universidad Popular Mexicana: cultura y revolución en la ciudad de México (1912-1920). Tesis de Doctorado en Historia. México. Universidad Nacional Autónoma de México. 
universidad centrado en la investigación. Ambos esquemas tienen como principal objetivo formar profesionales expertos en determinadas áreas o investigadores especializados en ciertos temas, y mediante el proceso de la evaluación, se aseguran de que los egresados posean el nivel de conocimientos requerido.

La evaluación implica un conjunto de controles, exigencias y reconocimientos que permiten al docente no sólo transmitir conocimientos, sino instaurar incluso en el alumno una conducta deseable, que implica la asistencia sistemática a las clases, el cumplimiento de los objetivos planteados en el programa, la lectura de los materiales proporcionados o sugeridos por el profesor, cierta costumbre y un método particular para el mejor aprovechamiento de los textos, etc.

Los controles y exigencias consisten en instrumentos tales como listas de asistencia, exámenes orales o escritos, entrega de ensayos, reseñas o resúmenes de lectura por parte de los alumnos, cuestionarios, guías de estudio, etc. Los reconocimientos, por su parte, se traducen en títulos, grados, diplomas, medallas y constancias, entre otras muchas formas de mostrar que el alumno ha sido capacitado en forma sistemática y con suficiente rigor dentro del ámbito de la academia.

En contraposición, a principios del siglo XX las universidades populares no utilizaban controles, ni otorgaban reconocimientos. Por citar un ejemplo, una de las mayores dificultades a las que se enfrenta quien investiga el pasado de estas instituciones es la búsqueda de listas de asistencia, ya que éstas generalmente no existen. Por ello, sólo mediante datos aislados, muchas veces indirectos, es posible inferir las características del alumnado.

El segundo problema que plantea el modelo educativo de la UPM puede ser resumido en una pregunta. Si el modelo educativo de las universidades populares no corresponde a los dos modelos "clásicos" antes descritos, ¿es correcto entonces dar a estas instituciones el nombre de "universidades"? A partir de los problemas antes planteados, fueron delineados y planteados los siguientes objetivos:

1. Describir, mediante la perspectiva de la historia, los lineamientos básicos que han caracterizado a las universidades desde su origen.

2. Caracterizar y comparar los modelos clásicos de universidad a principios del siglo XIX: universidad docente y universidad de investigación.

3. Caracterizar los propósitos de la extensión universitaria, como antecedente de las universidades populares.

4. Describir los orígenes, los fundamentos y el desarrollo de las universidades populares en Europa, como antecedente de la UPM.

5. Comparar algunos tipos de universidades populares en Europa -en particular en España-.

6. Caracterizar y relacionar el concepto de "educación libre" con el caso específico de la Universidad Popular Mexicana, surgida a principios del siglo Xx.

7. Caracterizar el modelo de universidad al que pertenecía la UPM. 
8. Explicar la relación existente entre el modelo educativo de la UPM y la sociedad de la época.

Con el propósito de llevar a cabo los objetivos anteriores, "fue programada al inicio una revisión de la bibliografía en que se aborda el tema." 3 Sin embargo, la revisión bibliográfica no logró proporcionar el cúmulo de información necesaria para el cumplimiento del objetivo planteado, lo cual motivó la ampliación del plan de trabajo, para que éste incluyera una investigación hemerográfica, y la consulta de dos archivos.

En general, la hemerografía no suele ser explorada aún por los historiadores con la misma asiduidad con la que son empleados documentos de archivo o libros, y tampoco es utilizada de manera sistemática como fuente de consulta. Sin embargo, el período planteado-los años transcurridos entre 1912 y 1920 constituye un lapso particularmente rico en acontecimientos culturales y educativos, que sólo eran asequibles desde la perspectiva proporcionada por los periódicos. Dado que la UPM sobrevivió durante los años más álgidos de la Revolución Mexicana en la ciudad de México, el estudio de la hemerografía de época permitió no sólo bocetar el derrotero de la institución educativa, sino también reconstruir en buena medida la vida cultural de la capital mexicana, dado que las actividades y los integrantes de la institución educativa se hallaban estrechamente vinculados con algunas de las iniciativas intelectuales más conocidas del período.

En cuanto a los archivos consultados, el Fondo Reservado de la Sociedad Mexicana de Geografía y Estadística, y el Archivo Pruneda, ambos permitieron profundizar no sólo en las características de la UPM, sino también en la interesante red de sociabilidad tejida en torno a la misma institución. La revisión documental, bibliográfica y hemerográfica permitió encontrar concordancias y precisar divergencias entre diversas instituciones educativas de la época.

Así, mediante la observación y el análisis de las fuentes, así como la aplicación del método comparativo a diversas experiencias educativas que tuvieron lugar en el

\footnotetext{
3 Entre las obras que abordan el tema se encuentran: VII COLOQUIO NACIONAL DE HISTORIA DE LA EDUCACIÓN. (1998): Educación Popular. Tenerife. Universidad de la Laguna. CURIEL DEFOSSÉ, Fernando. (1999): La Revuelta. Interpretación del Ateneo de la Juventud (1906-1929). México. UNAM / Instituto de Investigaciones Filológicas. CURIEL DEFOSSÉ, Fernando. (2001): Ateneo de la Juventud (A-Z). México. UNAM - Instituto de Investigaciones Filológicas. GARCIADIEGO DANTAN, Javier. (1986): Rudos contra cientificas. La Universidad Nacional durante la Revolución Mexicana. México. El Colegio de México / UNAM. KRAUZE, Enrique. (1985): Caudillos culturales de la Revolución Mexicana. México. SEP / Siglo XXI Editores. LEMPÉRIÉRE, Annick. (1992): Intellectuels, Etat et societé au Mexique. XXe siécle. Les clercs de la nation. Paris. Editions L'Harmattan. LOYO, Engracia. (1998): Gobiernos revolucionarios y educación popular en México (19121928). El Colegio de México. MATUTE, Álvaro. (1999): El Ateneo de México. México. Fondo de Cultura Económica. PEREZ SAN VICENTE, Guadalupe. (1979): La extensión universitaria. Notas para su historia. México. UNAM / Dirección General de Publicaciones. REYES, Alfonso. (1987): Universidad, política y pueblo. México. UNAM - Coordinación de Difusión Cultural / Instituto Politécnico Nacional. VASCONCELOS, José. (1987): José Vasconcelos y la Universidad. Introducción y selección de Álvaro Matute. México. UNAM Coordinación de Difusión Cultural.
} 
período planteado, fue posible reconstruir el modelo educativo específico de la UPM, e incluso proponer el perfil de egreso que constituía, probablemente, el propósito de la novedosa institución. Por último, fue necesario ubicar el modelo de la UPM en el contexto de los principales modelos educativos de los que era contemporáneo, y frente a los cuales se mostró como un sistema alternativo de enseñanza. Para ello fueron estudiados y presentados dichos modelos, en forma sucinta.

\section{Lineamientos Básicos que han Caracterizado a las Universidades. El Modelo Original de la Universidad}

¿Qué es una universidad? ¿Cuáles son los elementos que la definen como tal? ¿Cuáles los lineamientos básicos que permiten reconocerla e identificarla? Existen diversas perspectivas desde las cuales es posible responder a estas preguntas. Sin embargo, el enfoque histórico que se empleó para responder dichas interrogantes resultó particularmente revelador. Mediante la perspectiva histórica en particular la historia de los conceptos, fue posible rastrear los rasgos fundamentales persistentes hasta nuestros días- que constituyeron desde un principio a las instituciones que conocemos como "universidades".

María del Pilar Rábade plantea que, desde sus orígenes remotos en la "Europa medieval, la universidad fue entendida como una institución del saber identificable por ciertas características, poseedora de determinadas cualidades, generadas a partir de principios como la cohesión interna o la autonomía."4 Así explica Tamayo y Salmorán, las universidades de los siglos XI, XII o XIII -Bolonia, París, Oxford, Salamanca, Cambridge eran corporativas, pues estaban constituidas por personas y grupos en un gremio dedicado al saber; científicas, ya que procuraban obtener y transmitir juicios verdaderos, y difundir la idea de que el mundo podía ser explicado "racionalmente; universales, porque los conocimientos que generaban debían ser aplicables en ámbitos diversos, de forma universal; y autónomas, ya que ellas mismas se daban sus normas de gobierno." ${ }^{5}$

"De este modo, la universidad originaria, una confraternidad que reunía a profesores y alumnos en el propósito común de "compartir, de ampliar, de explorar el saber," trabajaba, según Díaz Novoa, bajo un esquema de sociedad plural donde "se convivía y se combatía con ideas, con la autoridad de la comprensión y la razón"” que podía corresponder

4 RÁBADE OBRADÓ, María del Pilar. (1996): Las universidades en la Edad Media. Madrid. Arco/Libros (Cuadernos de Historia), p. 18.

5 TAMAYO Y SALMORÁN, Rolando. (1987): La Universidad, epopeya medieval. México. Unión de Universidades de América Latina - UNAM/Instituto de Investigaciones Jurídicas, p. 116.

6 TORRES AGUILAR, Morelos. (2005): "El proceso permanente de la autonomía universitaria", en Revista de la Universidad de México. México. UNAM. Nueva Época. No. 11 (Enero), p. 58.

7 DÍAZ NOVOA, Gildardo. (2006): "Origen e idea de universidad", en Foro Responsabilidad Social: una mirada desde la Universidad. Colombia. Universidad de Antioquia - Vicerrectoría de Extensión, p. 7 
a dos tendencias o modelos: el parisino, organizado a partir de los profesores, y el boloñés, generado a partir de los estudiantes. En ambos casos se trataba de gremios, dado que universitas significa en el latín medieval, precisamente, "gremio" o "comunidad."»

\section{Universidad Docente y Universidad de Investigación: La Universidad y sus Modelos Durante el Siglo XIX y a Principios del XX}

Con el paso del tiempo, los modelos originarios dieron lugar a otros más complejos. En particular, para el tema de este estudio, resultaba importante caracterizar y comparar dos de ellos que constituían la idea de universidad a principios del siglo XIX. Mediante la historia de los conceptos y el análisis comparativo, se llegó a la conclusión de que la institución universitaria podía ser entendida en dicha época en formas disímiles, incluso contrapuestas, a partir de ambos modelos. "Existía, en primer lugar, el modelo de universidad docente o clásica, heredero del medioevo y enriquecido con la concepción napoleónica, cuyo objetivo central era la profesionalización de la enseñanza." ${ }^{9} \mathrm{Y}$ apareció también entonces un nuevo modelo, el humboldtiano, que aportaba una visión novedosa sobre la educación superior, al postular como principio la investigación científica, apoyada en la docencia avanzada o de postgrado como su función esencial. Debido a que tenía como misión la "búsqueda desinteresada del saber, este modelo defendía también la libertad de enseñanza y de aprendizaje."10

Un siglo después, en el ámbito latinoamericano, ambas posturas convivían o se yuxtaponían, ganando espacios en uno u otro sentido. En México, por ejemplo, la fundación de la Universidad Nacional de México en 1910, con la consiguiente creación de la Escuela Nacional de Altos Estudios, significó un triunfo aunque de alcances limitados- para la concepción humboldtiana, ya que posibilitaba la fundación de postgrados y la realización de investigaciones por parte de la casa de estudios. Así, la educación de corte positivista, desarrollada en la "Escuela Nacional Preparatoria y basada exclusivamente en la transmisión de conocimientos, sufrió una competencia que se venía a sumar a su propio declive."

Sin embargo, en el México de las primeras dos décadas del siglo XX, ninguno de los dos modelos contrapuestos pudo ser visto como un paradigma definitivo de educación

\footnotetext{
8 BALDERAS, Gonzalo. (2005): "Comentario", en Novena reunión del Seminario Universidad sin Condición. México. Universidad Iberoamericana, p. 2.

9 La concepción napoleónica implicaba también el control de la universidad por el Estado, que dotaba a la institución de recursos, pero al mismo tiempo intervenía en sus programas, quebrantando así su autonomía.

10 MORLES, Víctor. (2004): "La universidad latinoamericana actual: necesidad de replantear su misión", en Mundo Universitario. No. 7. Venezuela. Universidad de los Andes. (Abril), p. 3. 11 REYES, Alfonso. (2000): "Pasado inmediato", en Caso, Antonio et. al., Conferencias del Ateneo de la Juventud. México. UNAM-Coordinación de Humanidades (Nueva Biblioteca Mexicana, 5), p. 187. "La herencia de Barreda se fue secando en los mecanismos del método -recuerda Alfonso Reyes-. Se oxidaba el instrumental científico... la física y la química tendían ya a convertirse en ciencias de encerado, sin la constante corroboración experimental que las mentes jóvenes necesitan".
} 
superior. En el período revolucionario, la discusión en la prensa y el Congreso trascendió a veces la reflexión sobre los modelos educativos, y estuvo centrada más bien en la existencia o desaparición de la propia "Universidad Nacional, ya que por ese entonces se presentaron serios debates y argumentos sobre la necesidad de destinar los recursos gubernamentales a la educación rudimentaria, en lugar de fortalecer la educación superior." 12

Así pues, a partir de su creación, la Universidad Nacional se vio en la necesidad de construir y consolidar en forma paulatina su modelo educativo a lo largo de una década. La considerable duración de este proceso fue en parte consecuencia del también dilatado periplo que culminó en la propia fundación: Justo Sierra tuvo que esperar casi tres décadas ,para realizar un importante trabajo político y esperar pacientemente, hasta que encontró la ocasión propicia para el establecimiento de la casa de estudios. ${ }^{13}$

Tanto el modelo basado en la docencia llamado francés como el basado en la investigación conocido como alemán fueron fundamentados con mayor solidez sobre todo a partir de la tercera década del siglo XX, cuando Ortega y Gasset respaldó el modelo universitario germano, y todavía más adelante, en los años 50, cuando Karl Jaspers fortaleció la propuesta. En cuanto al modelo docente, o clásico, fue también a mediados de siglo que personajes como el Cardenal Newman, en Inglaterra, robustecieron la idea según la cual la "Universidad debía ser sólo un centro de enseñanza, de preservación del saber, en tanto que la investigación debía ser emprendida por organismos creados específicamente para desarrollarla." ${ }^{14}$

\section{La Extensión Universitaria como Antecedente de las Universidades Populares. Un Modelo Alternativo de Educación}

Para el estudio de este tema, fue realizada una revisión de la historia de la educación universitaria en Europa a fines del siglo XIX y a principios del XX. El estudio resultó ser de particular importancia, ya que gracias a él fue posible detectar algunas alternativas novedosas de enseñanza que fueron generadas durante esa época.

Estos modelos alternativos, que enriquecieron la idea que tenían diversos sectores de la sociedad sobre la institución universitaria, y que involucraron a numerosos intelectuales a principios del siglo XX, surgieron debido a que los modelos dominantes se habían visto rebasados en su intento por satisfacer las necesidades de educación universitaria de la colectividad.

\footnotetext{
12 EL IMPARCIAL. (1912): México, D. F. 22 de noviembre, p. 7. La Comisión de Instrucción Pública de la Cámara de Diputados discutió la propuesta de la Confederación Cívica Independiente, que pedía la clausura de la Universidad y de la Escuela Nacional de Altos Estudios.

13 ALVARADO, Lourdes. (1994): La polémica en torno a la idea de Universidad en el siglo XIX. México. UNAM-Centro de Estudios sobre la Universidad/Escuela Nacional Preparatoria, pp. 99-120.

${ }_{14}$ Ibídem., p. 4.
} 
Uno de estos modelos alternativos nació de manera natural, como un intento de las elites intelectuales, de mejorar y transformar las condiciones de vida de las capas humildes de la población, por medio de la enseñanza. El modelo, que tuvo por fundamento la extensión universitaria, rindió importantes frutos a ambos lados del océano. En principio, la extensión universitaria surgió en 1873, a partir de un grupo de estudiantes de la "Universidad de Cambridge que organizaron un exitoso ciclo de lecturas para adultos. Así fue creado el Sindicato para Lecturas Locales, conducido por James Stuart, asistente tutor de la propia Universidad."15

Años más tarde, Albert Mansbridge fundó la Workers Educational Association, integrada por miembros del partido laborista, hombres de iglesia e intelectuales que pretendían "proveer a la clase adulta trabajadora de facilidades para desarrollar sus actividades, y así trabajar más efectivamente por la emancipación social e industrial."16

En la década de 1880, la extensión universitaria fue desarrollada con gran éxito en los Estados Unidos, país donde la idea dio un interesante giro, pues en lugar de pretender llevar el pueblo a la Universidad, la nueva orientación proponía "llevar la Universidad al pueblo". "Así se explica el enorme entusiasmo generado por la extensión en la unión americana, donde la iniciativa se extendió a 28 estados, expansión que es posible documentar gracias a la preservación, hasta la fecha, de más de una veintena de textos sobre el tema, editados entre 1887 y $1916 . " 17$

\section{Orígenes y Desarrollo de las Universidades Populares en Europa. El Modelo de la Universidad Popular Parisina}

Para profundizar en este tema, se realizó un estudio histórico y un análisis comparativo sobre la creación, las convicciones y las principales ideas que se articularon en la fundación de las universidades populares en Europa a comienzos del siglo XX. Además, se compararon los principales propósitos que animaban a la extensión universitaria en relación con los que dieron origen a las universidades populares.

Se descubrió así que, si bien a partir de las universidades del mundo anglosajón se originó un nuevo y acertado modelo educativo, basado en la extensión universitaria, en el ámbito latino los intelectuales decidieron seguir otro camino, el de las universidades populares, que surgieron a fines del siglo XIX y se extendieron por Europa y América durante las dos primeras décadas del siglo XX.

Aunque la extensión universitaria fue desarrollada también en España y Francia, el modelo educativo aportado por estos países fue predominantemente el de la universidad popular. La idea de fundar una universidad popular surgió en París, tras la caída de la Comuna de Montreuil, una comunidad de obreros que trabajaba por el bien

\footnotetext{
15 MINUJIN ZMUD, Alicia. (1962): Extensión universitaria. Tesis de Licenciatura en Pedagogía. México. UNAM-Facultad de Filosofía y Letras, p. 7.

16 Ibídem., p. 8.

17 Ibídem., p. 471.
} 
común; a partir del hecho, los obreros, escarmentados de su experiencia comunista, se reunían en grupos a discutir cuestiones de sociología y metafísica, o bien de ciencias naturales, en los célebres Soirées ouvrières.

En este contexto, Jorge Deherme, un obrero tipógrafo, comenzó a editar y repartir la hoja volante La coopération des idées, que promovía la democracia mediante "la cooperación de todas las voluntades, de todas las ideas, de todos los intereses, no con la lucha". "El medio que Deherme planteaba para lograr esa cooperación era la educación, bajo la forma de una "enseñanza popular ético-social," 18 con el propósito de formar "hombres de voluntad enérgica, conciencias altas y esclarecidas, corazones ardientes, inteligencias sanas", es decir una elite proletaria que constituyera el núcleo vivo de una sociedad futura.

Así, en 1898, en el fondo de un patio de la calle de Paul Bert, "con una mesa sencilla, veinte taburetes, dos lámparas de petróleo y una silla," 19 fue organizado el primer ciclo de conferencias de la naciente universidad popular. El público asistente iba desde una muchedumbre la noche de la apertura, hasta no más de dos o tres personas, sin que esto motivara la suspensión de las conferencias. Y las contribuciones voluntarias de los asistentes, aunque inconstantes, permitieron un modesto progreso del local, de modo tal que gracias a ellas se compraron bancas e incluso se comenzó a formar una biblioteca.

Durante ese invierno, a principios de 1899, los intelectuales franceses se vieron enfrentados a la sociedad de su país a propósito del llamado "Affaire Dreyfus," ${ }^{20}$ por ese entonces la sociedad parisina, caracterizada por un nacionalismo acrítico y hasta crédulo, y por su apoyo incondicional al gobierno, los repudió, acusándolos de "oponerse a la masa de la nación y a su engrandecimiento". Expulsados, pues, de la esfera de la política, los intelectuales vieron en el pueblo llano, en el hombre de la calle, el nuevo objeto de su ideal, y en la educación el medio para realizarlo.

Así, escritores y artistas como Zola, France, Duclaux, Buisson, Tailhade y Séailles, entre muchos otros, se sumaron al esfuerzo pedagógico de Deherme, con tal entusiasmo que La coopération des idées se transformó rápidamente en una "Sociedad de

\footnotetext{
${ }_{18}$ MORENO MARTÍNEZ, Pedro Luis y SEBASTIÁN VICENTE, Ana. (2001): "Un siglo de Universidades Populares en España (1903-2000)", en Historia de la Educación. Revista interuniversitaria. Salamanca. Universidad de Salamanca. No. 20 (Separata), p. 163.

19 MIMENZA CASTILLO, Ricardo. (1919): "Las Universidades Populares", en El Pueblo. México, D. F. 25 de febrero, p. 2.

${ }^{20}$ COSER, Lewis. (1968): Hombres de ideas. El punto de vista de un sociólogo. México. Fondo de Cultura Económica (Sección de Obras de Sociología), p. 237. Como se recordará, Dreyfus, un capitán de ascendencia judía del Estado Mayor de Francia, fue acusado de espionaje en favor de Alemania, y al hallársele culpable fue condenado a cadena perpetua, pese a que había pruebas de su inocencia. Aunque algunos intelectuales como Zola pidieron al gobierno un nuevo juicio para Dreyfus, no fueron escuchados, y sí en cambio castigados: Zola mismo fue acusado de difamación y condenado a un año de prisión. Sin embargo, con el perdón y la rehabilitación otorgados al militar, se demostró que "los intelectuales, apoyados por la fuerza de la opinión pública, podían prevalecer sobre los hombres de poder".
} 
Universidades Populares" que pretendía organizar la enseñanza popular por todo el país. Se recaudaron así miles de francos, que sirvieron para instalar la primera "Universidad Popular" organizada como tal, la cual fue inaugurada en París, en octubre de 1899, con la conferencia "Educación y revolución," a cargo de Gabriel Séailles." ${ }^{11}$

Sobre los propósitos que animaban a la nueva organización educativa, Zola, uno de sus colaboradores más entusiastas, escribió:

\begin{abstract}
Es menester instruir a los obreros para su misión de ciudadanos libres, que sepan y quieran estar libres de absurdos, de dogmas y mortales errores religiosos, funestos para la libertad y la dignidad humanas. Mientras haya multitud de pobres de espíritu, habrá multitud de miserables, de bestias de carga, explotadas y devoradas por una infima minoría de ladrones y bandoleros. ${ }^{22}$
\end{abstract}

En la naciente institución, que pronto logró reunir más de dos mil adherentes, se ofrecían conferencias todas las noches, de manera ininterrumpida."Además había cursos de lenguas, fotografía, canto, taquigrafía, dicción y costura; consultas médicas, jurídicas y económicas, servicio barato de farmacia, y hasta un patronato para niños y un Teatro social." ${ }^{23}$ La biblioteca, en tanto, había logrado reunir más de tres mil volúmenes. El éxito de esta primera Universidad Popular dio origen a la multiplicación y la diversificación de la iniciativa a lo largo y ancho no sólo de Francia, sino de toda Europa.

Ahora bien, ¿qué diferencia había entre la extensión universitaria británica y la universidad popular francesa? La extensión universitaria, que tuvo su origen en Gran Bretaña pero que se multiplicó rápidamente, por ejemplo en Viena, Turín y Oviedo, propició la fundación de universidades populares que estaban adscritas a la figura y los recursos de una Universidad tradicional: realizaban sus actividades en las instalaciones de ésta, y disponían asimismo de sus profesores y sus métodos.

En cambio la universidad popular francesa, cuyo ejemplo fue seguido en Polonia, Bélgica e Italia, nació y se desenvolvió "de manera privada, independiente de la Universidad y de los poderes oficiales."24 Éste fue el modelo seguido por la Universidad Popular Mexicana.

Así, mientras la extensión universitaria recibía sumas considerables, otorgadas por las propias universidades tradicionales, las universidades populares del modelo francés sobrevivían mediante las contribuciones de sus socios, gracias a la voluble ayuda de los sindicatos, las cooperativas, y a veces hasta por el apoyo de los municipios.

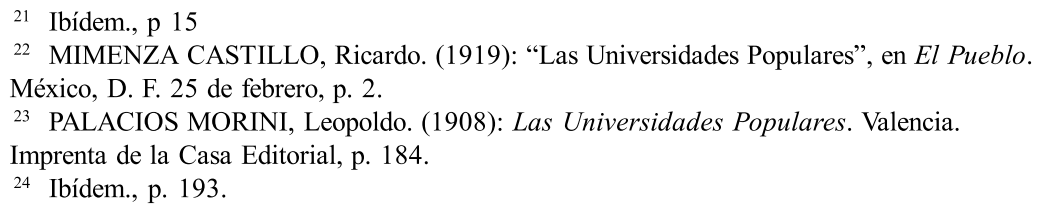


Pero el modelo francés no era homogéneo. Palacios divide a las universidades populares que existieron en Francia a comienzos del siglo XX en tres grupos: el primero recogía la tradición democrática de La coopération des idées, y así su enseñanza era una acción social orgánica que educaba "para un porvenir de libertad," 25 y no para el triunfo de determinada ideología; el segundo, en cambio, estaba constituido por instituciones obreras organizadas "para la lucha de clase, para la conquista de un poder público, el de la enseñanza"; por último, en los institutos populares la enseñanza realizada por católicos, según métodos racionales buscaba "la organización democrática, el florecimiento del movimiento sindical y la legislación del trabajo".

Esta diferenciación impulsa a Charles Guieysse a describir en 1901 la existencia de una dicotomía "entre aquellas Universidades Populares cuyas finalidades propendían a lograr la concordia y la paz social, y aquellas otras cuya prioridad era el desarrollo intelectual de los obreros, para que pudieran luchar contra las instituciones y lograr la justicia por sus propios esfuerzos." 26

\section{Las Universidades Populares en Europa a Principios del Siglo XX. El Caso Español}

Para profundizar en este tema, fueron estudiados diversos casos de universidades populares en Europa, y se realizó un esquema comparativo que permitió encontrar similitudes y diferencias entre ellos. En particular, fue analizada la creación de este tipo de instituciones educativas en España, ya que las universidades populares de la península, específicamente la de Madrid, influyeron en la fundación de la UPM.

En principio, cabe resaltar que las iniciativas de la extensión universitaria y la idea de la Universidad Popular cundieron rápidamente en Europa durante la segunda mitad del siglo XIX, período en el que se fueron generando las condiciones necesarias para la fundación de universidades populares o centros de extensión. "En Austria, por ejemplo, en 1860 ya se había fundado una Asociación Vienesa para la Instrucción de los Trabajadores, en tanto que en Bélgica, a partir del movimiento llamado "Antiegoísmo", se desarrollaron en 1870 algunas iniciativas de enseñanza." ${ }^{27}$ Leopoldo Palacios, testigo privilegiado de este proceso, describe la existencia de universidades populares o esfuerzos extensionistas en diversas ciudades a principios del siglo XX, como Turín, Ginebra, Bruselas, Lovaina, Gante y Viena.

El caso italiano es igualmente interesante. Con el apoyo de grandes escritores como Gabriel D'Annunzio, fue organizado en la península un buen número de universidades populares con un objetivo "en el que concurrían desinteresadamente

\footnotetext{
25 Ibídem., p. 194

26 MORENO MARTÍNEZ, Pedro Luis y SEBASTIÁN VICENTE, Ana. (2001): "Un siglo

de Universidades Populares en España (1903-2000)", en Historia de la Educación. Revista interuniversitaria. Salamanca. Universidad de Salamanca. No. 20 (Separata), p. 165.

27 ROSADA, Maria Grazia. (1975): Le Università popolari in Italia (1900-1918). Roma.

Editori Riuniti, p. 22.
} 
intelectualidad y buena voluntad": "organizar conferencias y lecciones para conducir a amplios estratos de la población a conocer los fundamentos conceptuales de la cultura científica, artística y literaria." ${ }^{28}$

La primera de estas instituciones surgió en Torino en 1900; muchas más habrían de seguir su ejemplo dentro de un plazo muy breve: Florencia, Roma, Milán, Bologna, Génova, Venecia, Liborno, Nápoles, Pisa, Padova, Parma, Palermo, Bari y Ferrara. Estas instituciones fueron los puntos de confluencia de intelectuales adscritos a las más diversas ideologías: socialistas, radicales, republicanos, progresistas, "liberales, católicos y anarquistas, entre otros." ${ }^{29}$ Pese a su apertura ideológica, sin embargo, varias universidades populares se fueron acercando en forma paulatina a una postura militante; así, en Milán, la idea de Universidad Popular fue sustituida por la de "Universidad Proletaria", que funcionó allí entre 1921 y 1926.

Pero la expansión del modelo de Universidad Popular trascendió el espacio occidental de Europa. En Alemania, por ejemplo, las universidades de "Léipzig, Berlín, Hamburgo y Munich organizaron los Hochschulvorträdge für Jederinann cursos de enseñanza superior para todo el mundo, que congregaban a miles de asistentes," ${ }^{30}$ mientras que en Hungría, el Szabad Lyceum fundado en 1893 reunía cada año a cerca de ocho mil oyentes en sus conferencias, y en Rusia las universidades ofrecían conferencias "a los obreros de los barrios pobres".

En suma, a fines del siglo XIX y a principios del XX se extendió en Europa una corriente educativa que se caracterizaba no sólo por su entusiasmo, su energía y su capacidad de trabajo, sino por la diversidad de sectores y grupos sociales en que se sustentaba. Dicha corriente desarrolló, por una parte, la extensión universitaria; y por la otra, propuso diversos modelos de educación popular, bajo los cuales fueron fundadas numerosas universidades populares a lo largo del continente. Sin importar sus diferencias, los modelos en cuestión perseguían en las diversas Universidades Populares de Francia, Bélgica o Italia, principios y líneas programáticas similares, tales como la "emancipación intelectual, moral y social de los trabajadores", la "neutralidad e independencia política" y la "popularización de la ciencia." 31

Dentro del contexto europeo, el caso de España es particularmente revelador. Aunque las universidades populares no surgieron en España de forma conjunta, sino como proyectos autónomos e independientes, presentaban ciertos rasgos comunes: provenían de iniciativas colectivas; sus promotores eran estudiantes, profesores, intelectuales o profesionales liberales pertenecientes a la pequeña y mediana burguesía liberal, reformista y próxima a círculos republicanos; y participaban en ellas intelectuales

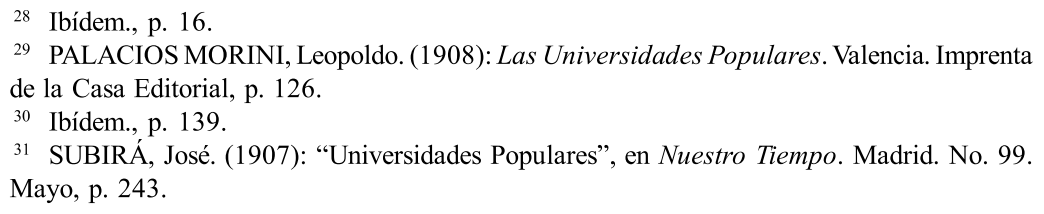


de prestigio o que llegarían a serlo con el paso del tiempo como Antonio Machado, que participó en la Universidad Popular de Segovia, Wenceslao Fernández Flores en la coruñesa, y Vicente Blasco Ibáñez en la valenciana.

La primera Universidad Popular española fue fundada en Oviedo; sus actividades perduraron durante una década y se extendieron a Gijón, Avilés y La Felguera, después de lo cual fueron fundadas seis instituciones similares entre 1903 y 1919, en Madrid, Sevilla, La Coruña, Segovia, y dos en Valencia, una de las cuales fue fundada por Blasco Ibáñez. ${ }^{32}$

Las Universidades Populares españolas poseían algunos rasgos distintivos. El primero de ellos era su carácter incluyente o interclasista: Posada señalaba que dichas instituciones no estaban destinadas

...exclusivamente hacia una clase determinada, aunque ésta [la clase obrera] sea la más numerosa, y económica y moralmente la más necesitada, sino hacia todo el pueblo, o sea a aquella masa que no encuentra en las privilegiadas instituciones de la enseñanza oficial los medios precisos para su cultura. ${ }^{33}$

Pero las Universidades Populares en España no sólo eran incluyentes en el plano social; también eran plurales, es decir, aceptaban en su seno las más diversas ideologías, como la Universidad Popular de Madrid, en donde cabían "todos los temperamentos, todos los partidos, todas las creencias", entendidas como diversas tendencias religiosas, políticas y sociales. ${ }^{\prime 34} \mathrm{Y}$ además de ser incluyentes y plurales, las Universidades Populares eran neutras, o dicho de otro modo, no eran instituciones militantes o beligerantes en el plano ideológico o el político. Como su proyecto no partía de estratos sociales populares, sino burgueses, y al estar inspiradas en el reformismo social krauso institucionista, las actividades de estas casas de estudios se planteaban más bien como "un medio para alcanzar la pacificación social". Esta característica atrajo en su momento algunas críticas, que reprochaban a las Universidades Populares

...un distanciamiento, una reducción al ámbito cultural, una falta de compromiso, en opinión de algunos, con una clase obrera en condiciones de explotación tanto económica como intelectual. ${ }^{35}$

Las Universidades Populares en España significaron una obra de renovación y regeneración social no exenta de utopía, de solidaridad humana en la que, según Posada, lo fundamental residía en

\footnotetext{
32 MORENO MARTÍNEZ, Pedro Luis; SEBASTIÁN VICENTE, Ana. (2001): "Un siglo de Universidades Populares en España (1903-2000)", en Historia de la Educación. Revista interuniversitaria. Salamanca. Universidad de Salamanca. No. 20 (Separata), p164.

33 POSADA, Adolfo. (1903): "Las Universidades Populares", en La Revista Socialista, No.

8. Madrid. 14 de abril, p. 202.

34 Ibídem., p. 202.

35 TIANA FERRER, Alejandro. (1992): Maestros, misioneros y militantes. La educación de la clase obrera madrileña, 1898 - 1917. Madrid. Ministerio de Educación y Ciencia, p. 283.
} 
...una hermosa aspiración científica, un anhelo educativo, un admirable deseo de mejorar, de elevarse por medio de la cultura, la cual no consiste sólo en saber unas cuantas cosas, sino en formarse de cierta manera... a introducir y difundir por las masas del pueblo que trabaja y no ha podido educarse: la Ciencia, la Filosofia, la Historia, el Arte, la Literatura, el Derecho, lo bello y lo útil. ${ }^{36}$

Así, las Universidades Populares tuvieron el propósito de luchar contra los tres enemigos más poderosos que, a juicio de Subirá, atenazaban la paz de los pueblos: "la ignorancia, la apatía y la intransigencia." ${ }^{37}$

El funcionamiento de las Universidades Populares en España permite entender la propia fundación de la Universidad Popular en México, pues es innegable la importancia y la influencia que representaron las primeras para los intelectuales mexicanos. Porque las numerosas similitudes entre estas instituciones educativas a ambos lados del océano no fueron obra de la casualidad, sino producto de una comunicación entre los intelectuales de España y los de México.

Hace ya años, cuando yo vivía en Madrid recordaba Ángel Zárraga en 1913, algunos amigos míos jóvenes y entusiastas, ateneístas empedernidos, Pedro González Blanco, Enrique Díez Canedo, Ángel Vegue y Galdoni, y muchos otros más, consagraban lo mejor de sus energías a la Universidad Popular de Madrid. Cuántas mañanas de domingo pasamos juntos en el Museo del Prado, enseñando las maravillas que encierra, a aquellos obreros, gente sencilla y ávida de revelaciones. ${ }^{38}$

Precisamente uno de estos ateneístas, Pedro González Blanco, habría de ser en 1912 el principal catalizador para la fundación de la Universidad Popular Mexicana, que nació en el marco de las actividades del Ateneo de México.

\section{La Educación Libre a Principios del Siglo XX en México}

Sobre este punto, se estudiaron diversos significados acerca del término "educación libre", con base en su utilidad para explicar la actuación de las instituciones educativas que basaban su trabajo en él a principios del siglo XX. Esta labor de selección resultó muy necesaria debido a que, en la actualidad, el término puede referirse a muy diversas actividades, dependiendo del contexto en que se utilice.

Una de las acepciones más comunes del término, relevante porque es utilizada aún en la actualidad, vincula a la educación libre con principios ideológicos radicales, o bien con propósitos de reivindicaciones sociales. "Pierre Mauroy, por ejemplo, señala

\footnotetext{
36 Ibídem., p 233-234.

37 SUBIRÁ, José. (1907): “Universidades Populares”, en Nuestro Tiempo, No. 99. Madrid. Mayo, pp. 243-244.

38 UNIVERSIDAD POPULAR MEXICANA. (1916): Boletín de la Universidad Popular Mexicana. México. D. F. (II, 2, junio), p. 89.
} 
que el principio de "educación libre y obligatoria" fue planteado en Francia desde 1793, como consecuencia de una combativa Revolución Francesa, que casi al mismo tiempo postulaba la Declaración de los Derechos del Hombre." 39 Anastasio Ovejero, por su parte, propone que el concepto tuvo su origen en las ideas anarquistas a "comienzos del siglo XX." ${ }^{40}$ Vista desde este enfoque, la educación libre se vincularía, por ejemplo, con ideas como la "educación integral" de Paul Robin, que pretendía fomentar en los niños "el derecho universal de la libertad". Y más aún, se relacionaría con iniciativas como las de la Escuela Moderna de Francisco Ferrer, quien en 1909 basaba la educación en los valores fundamentales de la solidaridad y la libertad.

Sin embargo, la corriente de educación libre a la que estaba adscrita la UPM era menos radical que las posturas antedichas, y presentaba características de identidad peculiares. Esta corriente entendía como "educación libre" una forma de enseñanza que ejercía la libertad desde tres perspectivas distintas: su fundamento pedagógico, su funcionamiento y su autonomía.

Desde la perspectiva pedagógica, esta corriente de educación libre planteaba como principio irrestricto la libertad de cátedra, es decir el derecho que tiene todo profesor de impartir los temas que le parezcan relevantes a partir de su sistema de valores y su universo de conocimientos. Desde el enfoque funcional, los centros de estudios adscritos a esta manera de pensar no establecían obligaciones a los alumnos, dejando en manos de éstos las decisiones sobre su propia formación. Dicho de otro modo, los educandos determinaban qué asignaturas cursaban y a qué conferencias asistían, de acuerdo a sus particulares intereses y a su propia voluntad de aprendizaje.

Desde la perspectiva autonómica, las escuelas libres postulaban y defendían con firmeza su independencia respecto a las dependencias gubernamentales, y por tanto se planteaban enormes retos para su supervivencia, tales como la organización efectiva y la creación de un conjunto de métodos para la consecución de recursos.

Dentro de la corriente ya descrita se inscriben varias propuestas culturales y educativas que tuvieron lugar en la época. Así, en forma paralela a la fundación de la UPM, surgieron no sólo instituciones como la Escuela Libre de Derecho, la Asociación de Educación Libre, la Escuela de Medicina Libre y la Escuela Libre de Música, sino muchas otras que, más allá del nombre, compartían el mismo propósito de divulgar conocimientos a públicos no cautivos sino, precisamente, libres. ${ }^{41}$

\footnotetext{
39 MAUROY, Pierre. (1989): “Las esperanzas de la Revolución”, en Revista Nueva Sociedad, No. 103. Buenos Aires.. Septiembre - Octubre, p. 119.

40 OVEJERO, Anastasio. (2005): “Anarquismo español y educación”, en revista Athenea Digital. pensamiento e investigación social. No. 8. Barcelona. Universidad Autónoma de Barcelona. Otoño, p. 147.

${ }^{41}$ TORRES AGUILAR, Morelos. (2008): "Instituciones e iniciativas culturales en la ciudad de México durante la Revolución Mexicana (1911-1919): Lucha armada y revolución intelectual", en Congreso Internacional "Dos Siglos de Revoluciones en México". Morelia. UNAM-Instituto de Investigaciones Históricas, p. 12.
} 


\section{La Universidad Popular Mexicana: un modelo singular de educación libre}

Una vez precisado el marco de referencia, fue posible reconstruir, al menos de manera provisional, el modelo educativo desempeñado por la Universidad Popular Mexicana. Se utilizó para ello un instrumento de análisis comparativo, mediante el cual fueron explorados factores de similitud o divergencia que presentaba la institución respecto a otras universidades populares, tanto en Europa como en América. Algunos de estos factores son: la procedencia del profesorado; la organización de la enseñanza en dos formas distintas, es decir cursos y conferencias aisladas; la naturaleza misma de las conferencias impartidas en la institución educativa; la relación entre la UPM y las esferas de la política y la ideología; y por último, las características que otorgaban una identidad a la casa de estudios.

Así encontramos que, en relación con sus antecesoras del viejo continente, la UPM se caracterizó por seguir un modelo más bien híbrido e incluyente, pues aunque seguía la corriente francesa, y en particular la línea original de La coopération des idées, contaba también con algunos elementos de la "extensión universitaria británica observados por Palacios," 42 ya que, por ejemplo, algunos de sus profesores eran universitarios que podrían ser considerados aristócratas. Y al igual que las "universidades populares europeas, la institución estaba encabezada por un grupo de intelectuales de primer orden." ${ }^{43}$

Por otra parte, la UPM sí pudo organizar cursos, y no sólo conferencias aisladas como ocurrió en Francia; además, si bien desarrolló una labor de predicación característica de las universidades populares francesas, también divulgaba los resultados de la investigación científica realizada por sus profesores. Por último, el programa de conferencias de la UPM, en lugar de estar lleno de "asuntos candentes de batalla", se acercaba más al de la University extension, que versaba "principalmente sobre literatura o historia," científicas y humanísticas en lugar de la presentación de un plan de acción revolucionario.

En este mismo sentido, la Universidad Popular Mexicana presenta notables diferencias con otras universidades populares surgidas durante el primer cuarto de siglo en Latinoamérica. A partir del Primer Congreso Internacional de Estudiantes Americanos, que tuvo lugar en Montevideo en 1908, y particularmente a partir de la Reforma de Córdoba en 1918, tomó cuerpo en el cono sur un modelo educativo que consideraba como principal misión de la universidad el servir al pueblo. Este modelo fomentó en los universitarios latinoamericanos de aquellos años una amplia "conciencia crítica de la sociedad, y activista de los movimientos políticos transformadores," ${ }^{45}$ por lo cual, la

\footnotetext{
42 Ibídem., p. 196.

43 Entre ellos Antonio Caso, Alfonso Reyes, Pedro Henríquez Ureña, Alfonso Caso, Manuel Gómez Morín, Vicente Lombardo Toledano, Ezequiel A. Chávez, Alfonso Pruneda, Martín Luis Guzmán.

44 Ibídem., p. 198.

45 Ibídem., p. 4.
} 
docencia y la investigación sólo tenían sentido si formaban parte de un proyecto político. En cambio, en la Universidad Popular Mexicana quedaban excluidas terminantemente "las cuestiones políticas y religiosas," ${ }^{46}$ con lo cual la casa de estudios se alejaba de la línea postulada por muchas de las instituciones derivadas del modelo de Córdoba. Ahora bien, según Fernando Salmerón, la Universidad Popular Mexicana fue "la primera institución libre de cultura en México," ${ }^{47}$ noción que emplea también Lombardo Toledano:

La generación de 1910... fundó la Universidad Popular Mexicana, el primer centro libre de cultura de nuestro país y la primera casa de divulgación de las ideas centrales de la vida, después de medio siglo de rebeldías espirituales ignoradas y de aceptación fervorosa o callada del positivismo imperante. ${ }^{48}$

Como ya se ha visto, durante el primer cuarto del siglo XX, los modelos tradicionales de universidad se vieron cuestionados por esta concepción nueva y avanzada, una idea educativa que se proponía extender los conocimientos de la manera más amplia al cuerpo social, en lugar de restringirlos, como patrimonio exclusivo de una clase intelectual afanosa de poder o de dinero. "Así, al modelo tradicional, se le opuso en Europa y América una importante corriente que promovía la fundación de instituciones de libre enseñanza que correspondían a lo que Sanín Cano definió como "nuevos tipos de impulso cultural." ${ }^{49}$

\section{El Modelo Educativo de la UPM y la Sociedad de la Época: Educación para el Ciudadano}

El ejercicio de reconstrucción del modelo educativo postulado por la UPM se presentaría en forma incompleta si no estuviera acompañado, en forma paralela, por una recuperación del modelo de alumno que la institución perseguía. Con este fin se realizó un análisis temático de las principales convicciones que animaban a los fundadores del centro educativo, y de las ideas sobre salud, sobre civismo, sobre moral y sobre respeto al bien común que incidieron en la configuración de los cursos y las conferencias ofrecidas por la institución.

En efecto, al modelo de educación libre representado por la Universidad Popular Mexicana correspondía un modelo específico de alumno. Para reconstruir dicho modelo de alumno algo aproximado a lo que ahora se conoce como perfil de egreso, es necesario considerar que la institución pretendía sobre todo formar "hombres y mujeres útiles a

\footnotetext{
46 UNIVERSIDAD POPULAR MEXICANA. (2000): "Acta Constitutiva de la Universidad Popular Mexicana”, en CASO, Antonio; REYES, Alfonso, et. al., p. 375.

47 SALMERÓN, Fernando. (1980): "Los filósofos mexicanos del siglo XX", en de la Cueva, Mario, et. al., Estudios de Historia de la Filosofía en México. México. UNAM-Facultad de Filosofía y Letras (Seminario de Filosofía en México), p. 254.

${ }^{48}$ LOMBARDO TOLEDANO, Vicente. (2000): "El sentido humanista de la Revolución Mexicana", en CASO, Antonio; REYES, Alfonso, et. Al, p. 168.

49 URBINA, Luis G. (1912): "La primera Universidad Popular Mexicana", en El Imparcial. México. 29 de noviembre, p. 5.
} 
la sociedad", porque la enseñanza tenía como principal propósito formar ciudadanos. Debido a esto, para entender el modelo educativo de la institución, es necesario conocer el modelo de ciudadano que ésta planteaba.

En primer lugar, en contraposición a la lucha armada del período revolucionario, que militarizaba la vida social, la Universidad Popular Mexicana civilizaba: desde el aula, y mediante la conferencia, mostraba un horizonte distinto, la posibilidad de un porvenir donde el saber, y no las balas, se convirtiera en el principio capaz de configurar el rostro de la nueva sociedad.

Este acto civilizatorio nos da una idea sobre qué tipo de ciudadano el nuevo mexicano pretendía crear la Universidad Popular: en primer lugar, uno sano, libre de vicios como el alcoholismo tan frecuente en ese entonces, y capaz de preservar su salud mediante la naciente medicina preventiva; además, uno consciente de su papel dentro de la sociedad, y por tanto, respetuoso de los derechos de los demás; y por si fuera poco, culto, pues con este afán se impartían numerosas conferencias sobre artes, ciencias y humanidades, y no sólo de técnicas u oficios.

"Para la construcción de este modelo, era necesaria la implementación de nociones avanzadas para la época." ${ }^{50}$ La medicina preventiva, es decir la higiene, sigue siendo una estrategia indispensable para los organismos de salud pública aún en nuestros días. "Cuando nuestra misión sea de prevención más que de curación escribió Pruneda, la humanidad habrá dado un paso enorme, se habrán salvado infinidad de vidas y se habrán ahorrado incontables sufrimientos." ${ }^{51}$ Además, el trabajo de prevención de la enfermedad es decir de conservación de la saludera contemplado por la Universidad Popular como una responsabilidad compartida entre distintos componentes de la sociedad:

...las autoridades y los individuos; las escuelas y otras instituciones que imparten educación ... el Gobierno dictará las disposiciones sanitarias de general observancia y cuidará de hacerlas cumplir; se esforzará igualmente por cuidar de la salubridad común. Las escuelas y las demás instituciones culturales tratarán de hacer llegar a todos los conocimientos higiénicos. Pero los individuos deben igualmente empeñarse en hacer lo que a ellos compete directamente, para conservar su propia salud, la de los suyos, e indirectamente la de la colectividad. ${ }^{52}$

De ahí que el propósito fundamental de la Universidad Popular, es decir formar ciudadanos útiles para la sociedad, requiriera necesariamente de la concurrencia de

\footnotetext{
${ }^{50}$ Estas nociones se hallan en las conferencias impartidas por los profesores de la UPM. Consultar: UNIVERSIDAD POPULAR MEXICANA: Boletín de la Universidad Popular Mexicana, México, D. F. Tomos I, II, III y IV, correspondientes a los años de 1915 a 1918.

51 PRUNEDA, Alfonso. (1917): La higiene del comerciante. Conferencia dada en el Anfiteatro de la Escuela Nacional Preparatoria la noche del 16 de julio de 1917, como primera de la Serie organizada por la Universidad Popular Mexicana en honor del Primer Congreso Nacional de Comerciantes. México. Imprenta Victoria, p. 9.

52 Ibídem., p. 9.
} 
individuos sanos. El segundo atributo del ciudadano modelo, su capacidad de respetar a los demás, fue un tema recurrente dentro de las conferencias universitarias de civismo. Tratar bien a los demás, saber oír a todos, entenderse con todos, pensar rectamente, sentir verguenza si no se trabaja, hacer siempre cosas mejores, tener el impulso de educarse etc.,eran algunas formas de comportamiento que los profesores de la Universidad Popular recomendaban a sus alumnos. Cabe señalar que de este modo, la institución planteaba una formación moral laica, dirigida a la formación de ciudadanos, en contraposición a la moral cristiana, dirigida a la formación de creyentes, que caracterizó a buena parte del sector educativo a fines del siglo XIX y principios del XX.

Por último, la cultura general del ciudadano modelo, según lo planteaba la "Universidad Popular, consistía en un conjunto de saberes muy vasto que incluía un sinnúmero de nociones sobre las artes, las ciencias y las humanidades; pero sobre todo, residía en la disposición y el permanente interés que el estudiante debía manifestar hacia el conocimiento." ${ }^{53}$

Diversas agrupaciones que participaron en la revolución intelectual coincidieron en esta búsqueda del nuevo ciudadano, que por sus virtudes y su sabiduría representaba un sujeto de gran utilidad para la colectividad de la cual formaba parte.

\section{CONCLUSIONES}

Analizadas desde la perspectiva del presente, las universidades populares en general, y la Universidad Popular Mexicana en particular, presentaban rasgos de libertad tan notorios a comienzos del siglo XX, que valdría la pena preguntarse si estas corporaciones pueden ser consideradas propiamente como universidades pese al hecho de que varias de ellas sobreviven aún.

Este cuestionamiento guarda una estrecha relación con el presente. Toda Universidad del siglo XXI, por libre que parezca o que pretenda parecer, es una institución ligada o mejor dicho atada a un conjunto de controles todavía más severos que los acostumbrados en el siglo XIX. Las universidades contemporáneas son evaluadas ahora no sólo ya desde su interior, desde su realidad interna y autonómica, sino desde el exterior, por organismos evaluadores y acreditadores que, al emitir estrictas observaciones y recomendaciones, defienden un paradigma sobre lo que debe ser la educación superior de nuestro tiempo. En este sentido, las universidades contemporáneas se hallan también insertas en el proceso globalizador que determina muchas otras esferas de la actividad humana.

\footnotetext{
${ }^{53}$ Sobre estos conceptos, consultar: UNIVERSIDAD POPULAR MEXICANA. (1918): Primer Almanaque de la Universidad Popular Mexicana. Año de 1919. México. Imprenta Victoria. REYES, Alfonso. (2000): "Misión y propósitos de la Universidad Popular Mexicana", en CASO, Antonio; REYES, Alfonso, et. al. Op., cit, p. 371. PRUNEDA, Alfonso. (1917): "La Universidad Popular Mexicana en su quinto año de labores (1916-1917). Informe del Rector de la institución”, en Boletín de la Universidad Popular Mexicana. Tomo III, 1917. México, p. 14.
} 
Sin embargo, al examinar el surgimiento de las universidades desde una perspectiva histórica, se encuentra que los rasgos básicos que cumple desde entonces toda universidad concuerdan con los planteamientos centrales de las universidades populares. Desde su origen, aquellos magnos centros de estudios fueron planteados como instituciones de saber corporativas, científicas, universales y autónomas; y han constituido confraternidades, gremios o comunidades que reúnen a profesores yalumnos en el propósito común de compartir, ampliar y explorar el saber, a partir de la autoridad de la comprensión y la razón.

Si se parte de esta definición de carácter histórico, es indudable que las universidades populares cumplen todos y cada de los objetivos ya descritos, y de las características antes señaladas. Además, es importante considerar que, aunque los modelos más conocidos de universidad que funcionaban en el mundo durante las primeras dos décadas del siglo XX una universidad docente y otra investigadora y la idea misma de "universidad" se hallaban en pleno desarrollo durante el período estudiado, diversos sectores cuestionaban al mismo tiempo su significado social.

Los intelectuales que criticaban el elitismo de las universidades tradicionales construyeron como alternativa una corriente de pensamiento que transitó por dos caminos. Mediante el primero de ellos, desarrollado en países como Inglaterra y Estados Unidos, fueron creadas diversas instituciones que desempeñaban labores de extensión universitaria. La segunda vía dio lugar, en naciones como Francia o España, a la fundación de universidades populares. Ambos movimientos proporcionaron a las instituciones universitarias un conjunto de convicciones, estrategias e instrumentos que permitieron a éstas acercarse a la sociedad, proporcionando así conocimientos a amplios sectores que antes no tenían acceso a la educación superior.

Tanto en Europa como en América, la extensión universitaria y las universidades populares cumplieron con su labor de acercar el saber a las capas sociales más pobres. Y si bien existían notables matices, e incluso profundas diferencias entre las diversas instituciones que socializaban de esta manera los conocimientos, el propósito común de llevar "la universidad a la calle" fue perseguido y cumplido, con mayor o menor éxito, por todas ellas.

En México, la Universidad Popular Mexicana se insertó de manera natural en el vasto y fructífero proceso ya mencionado. Su modelo educativo se presentó en su momento como un plan alternativo respecto a los modelos pedagógicos tradicionales de su tiempo, ya que no competía con el tipo de enseñanzas impartidas en otros centros de educación superior. Por ello, como lo escribió Alfonso Reyes, esta casa de estudios constituyó principalmente una "escuela para ciudadanos", o dicho de otro modo, una casa de estudios que formaba "hombres y mujeres plenamente útiles a la sociedad" ${ }^{54}$

\footnotetext{
${ }^{54}$ REYES, Alfonso. (1912): "Misión y propósitos de la Universidad Popular Mexicana", en Caso, Antonio et. al., Conferencias del Ateneo de la Juventud. México. UNAM-Coordinación de Humanidades (Nueva Biblioteca Mexicana, 5), p. 374.
} 
Por otra parte, el modelo "libre" de la UPM corresponde también a una vasta corriente educativa que tuvo lugar en México a principios del siglo XX, y que dio origen a varias escuelas llamadas "libres", las cuales desarrollaban un modelo universitario distinto al desempeñado por la Universidad Nacional de México o la Escuela Nacional Preparatoria.

Los contemporáneos de estas instituciones -y en particular de la UPM- al descubrir en ellas características singulares y una propuesta educativa específica, dentro del contexto de la época, bautizaron como "libre" al modelo alternativo de enseñanza que representaban.

Efectivamente, el modelo de educación libre de la Universidad Popular se presentó en su momento como una alternativa viable para la enseñanza de las capas humildes de la población en la ciudad de México durante el período revolucionario. Por esta razón, a pesar de que sólo recibía donativos privados, y no recursos públicos, la institución logró subsistir durante ocho años en el período más álgido de la Revolución.

Tras la desaparición de la casa de estudios, su ejemplo y su modelo fueron retomados por José Vasconcelos, y posteriormente por Alfonso Pruneda, quien tras su rectorado en la Universidad Popular "entre 1913 y 1920, supo aprovechar las experiencias que había obtenido en ésta para iniciar un incomparable proyecto de extensión universitaria entre 1924 y 1928, cuando estuvo al frente de la Universidad Nacional de México." 55

\section{FUENTES}

\section{ARCHIVOS}

ARCHIVO PRUNEDA. Cuernavaca.

SOCIEDAD MEXICANA DE GEOGRAFÍA Y ESTADÍSTICA. Fondo Reservado. Ciudad de México.

\section{FUENTES PRIMARIAS}

El Imparcial. (1912): “La Universidad Popular”, México, D. F., 22 de noviembre.

\footnotetext{
55 Sobre estos temas, consultar: CHÁVEZ, Ezequiel A. (1924): La situación actual de la Universidad Nacional de México. México. Talleres Gráficos del Departamento Editorial de la Secretaría de Educación. SECRETARÍA DE EDUCACIÓN PÚBLICA. (1926): La educación pública en México a través de los mensajes presidenciales desde la consumación de la independencia hasta nuestros dias. México. Publicaciones de la Secretaría de Educación. JIMÉNEZ RUEDA, Julio. (1955): Historia jurídica de la Universidad de México. México. UNAM - Facultad de Filosofía y Letras.
} 
Extensión universitaria y universidades populares

MIMENZA CASTILLO, Ricardo. (1919): “Las Universidades Populares”, en El Pueblo. México, D. F. 25 de febrero.

PRUNEDA, Alfonso. (1917): La higiene del comerciante. Conferencia dada en el Anfiteatro de la Escuela Nacional Preparatoria la noche del 16 de julio de 1917, como primera de la Serie organizada por la Universidad Popular Mexicana en honor del Primer Congreso Nacional de Comerciantes. México. Imprenta Victoria.

TORRES AGUILAR, Morelos. (2008): "Instituciones e iniciativas culturales en la ciudad de México durante la Revolución Mexicana (1911-1919): Lucha armada y revolución intelectual", en Congreso Internacional "Dos Siglos de Revoluciones en México". Morelia. UNAM-Instituto de Investigaciones Históricas. p. 1-19. Puede ser consultado en http://www.centenarios.unam.mx/pdfs/memorias/morelos_torres.pdf

UNIVERSIDAD POPULAR MEXICANA (1915): Boletín de la Universidad Popular Mexicana, México, D. F. Diciembre. Vol. I. No. 8.

UNIVERSIDAD POPULAR MEXICANA (1916): Boletín de la Universidad Popular Mexicana, México, D. F. Marzo. Vol. II. No. 1.

UNIVERSIDAD POPULAR MEXICANA (1916): Boletín de la Universidad Popular Mexicana, México, D. F. Junio. Vol. II. No. 2.

UNIVERSIDAD POPULAR MEXICANA (1916): Boletín de la Universidad Popular Mexicana. México. Diciembre. Tomo II. No. 4.

UNIVERSIDAD POPULAR MEXICANA (1917): Boletín de la Universidad Popular Mexicana, México, D. F. Vol. III.

\section{PONENCIAS}

DÍAZ NOVOA, Gildardo. (2006): "Origen e idea de universidad”, en Foro Responsabilidad Social: una mirada desde la Universidad. Colombia. Universidad de Antioquia.

BALDERAS, Gonzalo. (2005): "Comentario", en Novena reunión del Seminario Universidad sin Condición. México. Universidad Iberoamericana.

\section{SELECCIÓN BIBLIOGRÁFICA}

ALVARADO, Lourdes. (1994): La polémica en torno a la idea de Universidad en el siglo $X I X$. México. UNAM - Centro de Estudios sobre la Universidad / Escuela Nacional Preparatoria.

CASO, Antonio y REYES, Alfonso, et. al. (2000): Conferencias del Ateneo de la Juventud. México. UNAM-Coordinación de Humanidades.

CHÁVEZ, Ezequiel A. (1924): La situación actual de la Universidad Nacional de México. México. Talleres Gráficos del Departamento Editorial de la Secretaría de Educación. 
COSER, Lewis. (1968): Hombres de ideas. El punto de vista de un sociólogo. México. Fondo de Cultura Económica.

CURIEL DEFOSSÉ, Fernando. (2001): Ateneo de la Juventud (A-Z). México. UNAM Instituto de Investigaciones Filológicas.

CURIEL DEFOSSÉ, Fernando. (1999): La Revuelta. Interpretación del Ateneo de la Juventud (1906-1929). México. UNAM - Instituto de Investigaciones Filológicas.

DE LA CUEVA, Mario, et. al. (1980): Estudios de Historia de la Filosofía en México. México. UNAM-Facultad de Filosofía y Letras (Seminario de Filosofía en México).

DÍAZ NOVOA, Gildardo. (2006): “Origen e idea de universidad”, en Foro Responsabilidad Social: una mirada desde la Universidad. Colombia. Universidad de Antioquia Vicerrectoría de Extensión.

GARCIADIEGO DANTAN, Javier. (1986): Rudos contra cientificos. La Universidad Nacional durante la Revolución Mexicana. México. El Colegio de México / UNAM.

JIMÉNEZ RUEDA, Julio. (1955): Historia jurídica de la Universidad de México. México. UNAM - Facultad de Filosofía y Letras.

KRAUZE, Enrique. (1985): Caudillos culturales de la Revolución Mexicana. México. SEP / Siglo XXI Editores.

LEMPÉRIÉRE, Annick. (1992): Intellectuels, Etat et societé au Mexique. XXe siécle. Les clercs de la nation. Paris. Editions L'Harmattan.

LOYO, Engracia. (1998): Gobiernos revolucionarios y educación popular en México (19121928). El Colegio de México.

MATUTE, Álvaro. (1999): El Ateneo de México, México. Fondo de Cultura Económica.

MIMENZA CASTILLO, Ricardo. (1919): "Las Universidades Populares", en El Pueblo. México, D. F. 25 de febrero.

MINUJIN ZMUD, Alicia. (1962): Extensión universitaria. Tesis de Licenciatura en Pedagogía. México. UNAM-Facultad de Filosofía y Letras.

MORENO MARTÍNEZ, Pedro Luis y SEBASTIÁN VICENTE, Ana. (2001): "Un siglo de Universidades Populares en España (1903-2000)", en Historia de la Educación. Revista interuniversitaria. Salamanca. Universidad de Salamanca. No. 20 (Separata)

MORLES, Víctor. (2004): "La universidad latinoamericana actual: necesidad de replantear su misión”, en Mundo Universitario. No. 7. Venezuela. Universidad de los Andes. (Abril)

PALACIOS MORINI, Leopoldo. (1908): Las Universidades Populares. Imprenta de la Casa Editorial. Valencia.

PEREZ SAN VICENTE, Guadalupe. (1979): La extensión universitaria. Notas para su historia. México. UNAM / Dirección General de Publicaciones. 
Extensión universitaria y universidades populares

POSADA, Adolfo. (1908): Pedagogía. Valencia. F. Sempere y Compañía Editores, S.A.

QUINTANILLAOSORIO, Susana. (1990): El Ateneo de la Juventud: balance de una generación. Tesis de doctorado en Pedagogía. México. UNAM - Facultad de Filosofía y Letras.

RÁBADE OBRADÓ, María del Pilar. (1996): Las universidades en la Edad Media. Madrid. Arco/Libros (Cuadernos de Historia).

REYES, Alfonso. (1987): Universidad, política y pueblo. México. UNAM - Coordinación de Difusión Cultural / Instituto Politécnico Nacional.

ROSADA, Maria Grazia. (1975): Le Università popolari in Italia (1900-1918). Roma. Editori Riuniti.

SECRETARÍA DE EDUCACIÓN PÚBLICA. (1926): La educación pública en México a través de los mensajes presidenciales desde la consumación de la independencia hasta nuestros días. México. Publicaciones de la Secretaría de Educación.

TAMAYO Y SALMORÁN, Rolando. (1987): La Universidad, epopeya medieval. México. Unión de Universidades de América Latina / UNAM - Instituto de Investigaciones Jurídicas.

TIANA FERRER, Alejandro. (1992): Maestros, misioneros y militantes. La educación de la clase obrera madrileña, 1898 - 1917. Madrid. Ministerio de Educación y Ciencia.

TORRES AGUILAR, Morelos. (2006): La Universidad Popular Mexicana: cultura y revolución en la ciudad de México (1912-1920). Tesis de Doctorado en Historia. México. UNAM-Facultad de Filosofía y Letras.

UNIVERSIDAD POPULAR MEXICANA. (1918): Primer Almanaque de la Universidad Popular Mexicana. Año de 1919. México. Imprenta Victoria.

VASCONCELOS, José. (1987): José Vasconcelos y la Universidad. Introducción y selección de Álvaro Matute. México. UNAM / Coordinación de Difusión Cultural.

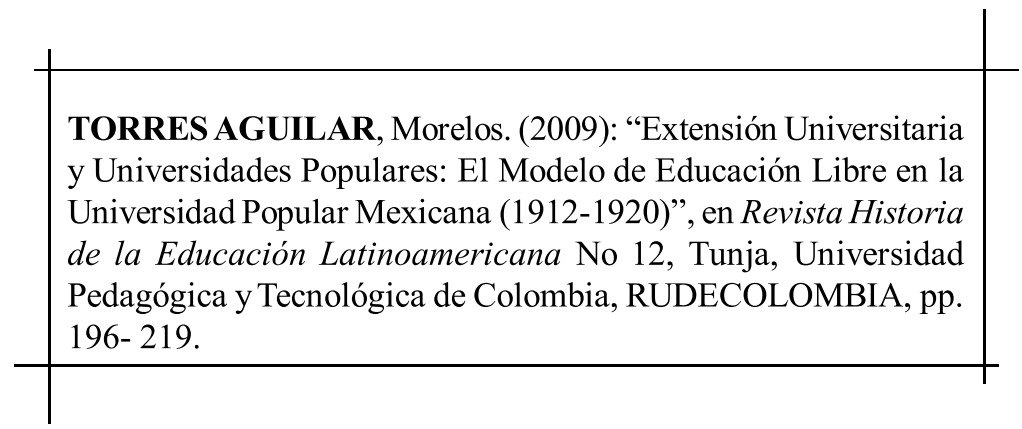

Rhela. Vol. 12. Año 2009, pp. $196-219$ 